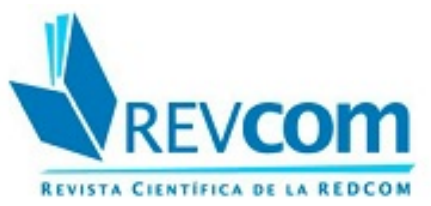

REVCOM. Revista científica de la red de carreras de Comunicación Social

ISSN: 2451-7836

redcom.revcom@gmail.com

Universidad Nacional de La Plata

Argentina

\title{
El anti-populismo en la Argentina del siglo XXI o cuando el odio se vuelve un factor político estructurante
}

Biglieri, Paula; Perelló, Gloria

El anti-populismo en la Argentina del siglo XXI o cuando el odio se vuelve un factor político estructurante REVCOM. Revista científica de la red de carreras de Comunicación Social, núm. 10, 2020

Universidad Nacional de La Plata, Argentina

DOI: https://doi.org/10.24215/24517836e031 


\title{
El anti-populismo en la Argentina del siglo XXI o cuando el odio se vuelve un factor político estructurante
}

\author{
Anti-populism in Argentina in the 21st century or when hate becomes a structuring political factor \\ Anti-populismo na Argentina no século XXI ou quando o ódio se torna um fator político estruturante
}

Paula Biglieri

DOI: https://doi.org/10.24215/24517836e031

Consejo Nacional de Investigaciones Cientificas y Técnicas

(CONICET). Universidad Nacional de La Plata,

Argentina

paulabiglieri@hotmail.com

Recepción: 02 Mayo 2020

Aprobación: 26 Mayo 2020

Gloria Perelló

Universidad de Buenos Aires. Universidad Nacional de

Moreno, Argentina

g_perello@hotmail.com

Recepción: 02 Mayo 2020

Aprobación: 26 Mayo 2020

\section{Resumen:}

Las autoras del artículo presentan una interpretación sobre los usos del odio en la vida política de la Argentina reciente. Específicamente apuntan a desentrañar en qué forma el odio funciona como factor estructurante del anti-populismo, a partir de la experiencia de la Alianza Cambiemos en el gobierno entre 2015 y 2019. La estrategia argumentativa avanza a partir de indicios -siguiendo la propuesta del paradigma indicial- que se toman de fragmentos de tres piezas discursivas de amplia repercusión pública. Y se utilizan herramientas teóricas ofrecidas por el psicoanálisis (tanto freudiano como lacaniano) así como por la propuesta de análisis del discurso de Laclau y Mouffe.

Palabras Clave: Neoliberalismo, Populismos, Democracia, Odio, Lazos Sociales.

\section{ABSTRACT:}

The authors develop an interpretation of the uses of hatred in the recent Argentinean political life. They try to unravel how hatred works as a structuring factor of anti-populism, specifically considering the experience of the political alliance 'Let's Change' in power 2015-2019. The argumentative strategy follows the traces -according to the evidential paradigm-taken from three discursive pieces that had a major public impact. And it uses theoretical tools offered by psychoanalysis (in both Freudian and Lacanian versions) as well as the discourse analysis perspective of Laclau and Mouffe.

KEYWORDS: Neoliberalism, Populisms, Democracy, Hate, Social Ties.

\section{Resumo:}

As autoras do artigo apresentam uma interpretação sobre os usos do ódio na vida política da recente Argentina. Elas propõem desvendar como o ódio funciona como fator estruturante do anti-populismo a partir da experiência da "Alianza Cambiemos" no governo entre 2015 e 2019. A estratégia argumentativa avança a partir de pistas de fragmentos de três peças discursivas de ampla repercussão pública, que são analizadas a partir de uma proposta teórica desde a psicanálise (tanto freudiano quanto lacaniano), e tambem desde o análise do discurso de Laclau e Mouffe.

Palavras-Chave: Neoliberalismo, Populismos, Democracia, Ódio, Laços Sociais.

"La grieta" fue la metáfora utilizada por Jorge Lanata ${ }^{1}$ en uno de los discursos que dio, cuando en el año 2013 recibió tres premios Martín Fierro ${ }^{2}$, para describir el antagonismo político que ha atravesado a la Argentina desde comienzos del siglo XXI. Según su visión el kirchnerismo "provocó” una "división irreconciliable" 
-la grieta - en la sociedad argentina estableciendo una oposición dicotómica entre kirchneristas vs. antikirchneristas, que lejos de acotarse a controversias políticas alcanzó a la cultura, quebrando vínculos laborales y profesionales e inclusive penetrando el espacio privado mismo cercenando así a familias, amistades, noviazgos, etc. Consideró además que la grieta es el mayor de los males que sufrimos los argentinos ("lo peor que nos pasa"), que llegó para quedarse ("va a trascender a los gobiernos"), tiene antecedentes ("la última vez que pasó fue en los años 50 y esa grieta duró 50 años") y que nadie puede arrogarse para sí la representación de la patria, ni de la verdad ("nadie tiene el copyright de la patria ni de la verdad"). El discurso estelar de aquella noche fue suplementado por otro breve discurso en el que consignó que la destinataria de sus premios era la entonces presidenta Cristina Fernández de Kirchner ("un último deseo se lo dedico a Cristina que lo mira por tv") y por las declaraciones que ofreció al salir de la gala en las que afirmó que "los kirchneristas son chorros con máscaras del Che Guevara" ${ }^{3}$. Sin haber dejado nunca su línea editorial anti-kirchnerista, tres años más tarde el 16 de octubre de 2016, en el mismo multipremiado programa Periodismo para todos, arremetió con una agresiva editorial que cerró de la siguiente manera: "Ahora, usted sin nada es solo una pobre vieja enferma y sola peleando contra el olvido y arañando desesperadamente un lugar en la historia que ojalá la juzgue como la mierda que fue". ${ }^{4}$

Traer puntualmente estas piezas de Lanata nos resulta interesante porque nos sirven como un indicio a partir del cual elaborar una interpretación de los usos del odio en la vida política de la Argentina reciente. Según nuestra conjetura, es un indicio de que el odio - ese sentimiento que la Real Academia Española define como la "antipatía y aversión hacia algo o hacia alguien cuyo mal se desea" y el Diccionario de María Moliner como la "repulsión hacia alguien, acompañado de deseo de causarle o de que le ocurra algún daño o la repugnancia violenta hacia una cosa, que hace que no se pueda soportar"- funciona como factor estructurante del anti-populismo. Para proceder a partir de indicios nos apoyamos en la propuesta de Carlo Ginzburg (2008), quien elaboró la tesis del paradigma indicial. Este historiador italiano sostuvo que dicho paradigma ha sido el método de conocimiento practicado desde tiempos remotos por los cazadores. Es la práctica de recopilación e interpretación de rastros o huellas que, puestos en relación entre sí, posibilitan la elaboración de un sentido a partir de un objeto (presa) ausente. Es decir, se trata de la identificación de elementos marginales -indicios- que abren el juego a la sensibilidad, la inteligencia y la creatividad para dar cuenta de aquello que no está delimitado en el espacio de lo social sedimentado. A modo de ilustración Ginzburg trae la fábula oriental Zadig que cuenta la historia de tres hermanos que reconstruyen la figura del camello, a través de la recolección de una serie de indicios, un animal que jamás habían visto. Ubica también la práctica del paradigma indicial en el psicoanálisis de Sigmund Freud, en las pesquisas de las novelas de detectives de Arthur Conan Doyle y su personaje Sherlock Holmes y en la crítica del arte desarrollada por el médico italiano Giovanni Morelli (quien durante años mantuvo su trabajo bajo los pseudónimos Iván Lermolieff y Johannes Schuartze). El paradigma indicial asume la posibilidad de que la verdad del conocimiento siempre toma una vía marginal e indirecta y que resulta constitutivamente opaca y fragmentaria, en oposición al paradigma positivista que postula el acceso al conocimiento de la verdad en la medida en que supone que las cosas son idénticas a sí mismas y se pueden conocer a través de una relación de correspondencia punto por punto con una representación de sí mismo. Esto es, supone la posibilidad de un conocimiento completamente acabado y transparente. Por el contrario, el paradigma indiciario postula un saber conjetural ya que sugiere que las cosas no son meramente lo que son puesto que la cosa no puede coincidir consigo misma, ni capturarse plenamente. En todo caso, se trata de una verdad siempre maldita, al decir del psicoanálisis lacaniano, la verdad (y aquí agregamos: del conocimiento) lejos está de pertenecer plenamente a un significante, por lo tanto, la verdad será siempre mal-dicha, o lo que es lo mismo, mediodicha (Lacan: 1972, 478).

Podemos decir que las piezas de Lanata en tanto posicionamiento político resultan un elemento marginal o menor en el contexto de un entramado discursivo mucho más amplio como es el espacio social que atañe a la Argentina. Sin embargo, estos elementos que ofreció Lanata, desde el paradigma indicial adquieren otra 
relevancia, en principio porque él fue uno de los protagonistas "estrella" de la línea editorial anti-kirchnerista que el Grupo Clarín (el conglomerado multimedia más poderoso de la Argentina) desarrolló, difundió y aún sostiene, por lo menos desde la disputa entre el gobierno de Cristina Fernández de Kirchner y las patronales agropecuarias en 2008..$^{5}$ Pero por sobre todo se tornan importantes por una serie de otras cuestiones. En primer lugar, porque si tomamos lo social como un terreno discursivo (Laclau y Mouffe, 1985) los dichos de Lanata se vuelven un indicio del poder (político) del Grupo Multimedia Clarín, en la medida en que evidencia su capacidad para tallar significantes y significados en el espacio social. Baste recordar el ejemplo del significante "la grieta", que a partir de su enunciación inicial comenzó a circular ampliamente en el entramado social concitándose como el diagnóstico definitivo respecto de un mal que padecemos los argentinos. Es decir, "la grieta" fue el significante que logró adosarle un sentido negativo a la división antagonista del espacio social en dos lugares de enunciación ("el pueblo" vs. "sus enemigos") que proponía el kirchnerismo como eje motor de la disputa política en pos de una ampliación de derechos. ${ }^{6}$ No es casual que la principal fuerza de la oposición (la Alianza Cambiemos - AC-) haya usado el sentido negativo de la "la grieta" en su campaña electoral de 2015. "La grieta" fue uno de los elementos desde el cual la AC pudo eficazmente presentarse a sí misma como la fuerza política antitética del kirchnerismo ya que venía a "unir a los argentinos", justamente, erradicando "la grieta" y terminando con el culpable de dicho mal, el kirchnerismo. ${ }^{7}$ En segundo lugar, es un indicio de que la AC que llevó a Mauricio Macri a la Presidencia de la Nación entre 2015 y 2018, fue mucho más allá que una mera alianza de partidos políticos. Se trató más bien de un entramado complejo (anti-kirchnerista) que además de partidos políticos incluyó a los medios de comunicación dominantes, el establishment financiero, sectores del poder judicial, las grandes corporaciones económicas nucleadas en la Asociación Empresaria Argentina, las organizaciones patronales del campo, diversas ongs, fundaciones, etc. Y, en tercer lugar, porque es un indicio de cómo el odio puede volverse un factor fundamental en la política. Y aquí yace el meollo de nuestro interés ya que el supuesto que esbozamos parte de las siguientes preguntas: ¡cuál es el lugar del odio en el anti-populismo? ¿Es acaso un afecto secundario o podemos pensarlo como un factor estructurante? Nos proponemos entonces explorar estos interrogantes a partir de la experiencia de la AC.

\section{EL ANTI-POPULISMO O CUANDO EL ODIO SE VUELVE UN FACTOR POLÍTICO ESTRUCTURANTE}

La noción de anti-populismo ha adquirido reciente protagonismo en los debates académicos europeos. Antonis Galanopoulos y Yannis Stavrakakis (2019) analizaron como en el anti-populismo en Grecia ha sistemáticamente apelado a la idea de que existe una correlación entre posverdad y populismo, dentro del discurso normativista que sustenta la implementación de las políticas de austeridad desde 2010. Para los anti-populistas griegos la posvedad y/o fake news y el populismo son considerados patologías que se refuerzan mutuamente y que han desviado a Grecia de los estándares de "normalidad" de los países europeos, necesitando en consecuencia "guía, disciplina, e inclusive castigo para poner su casa en orden y ser rehablitado dentro de la familia de los países 'normales' de Europa". Lo interesante es que estos autores logran desentrañar que la posición anti-populista nace de una idea de superioridad epistémica sustentada en la posesión de una (sola) verdad y en la encarnación de una racionalidad superior, que se presenta a sí misma como neutral y no política. Sólo así el populismo se vuelve lo opuesto a la normalidad y "la sinécdoque de todo lo que es patológico en la política griega: la irresponsabilidad, la demagogia, la inmoralidad, la corrupción, la destrucción, el irracionalismo" (Galanopoulos y Stavrakakis, 2019). Mientras que en un breve texto Galanopoulos (2020) define al anti-populismo como "una lógica particular que busca defender y reproducir el orden establecido desacreditando las demandas formuladas en el nombre del pueblo. El objetivo último de la lógica anti-populista es la defensa del orden, la preservación del status quo y la normal, ininterrumpida reproducción del establishment”. Benjamin Moffitt (2020) describe el anti-populismo de manera crítica. Considera que "a diferencia de otros 'ismos', el anti-populismo no posee una clara disposición ideológica o 
modo de gobernanza sino que más bien es una rara mezcla de ideología y aliados estratégicos cooperando en una coalición temporal (...) pero que sí comparten una visión de cómo se debe 'hacer' política”. Enumera entonces los componentes de dicha visión: a) si los populistas apelan a la división "el pueblo" en contra de "las élites", los anti-populistas consideran que es una forma bruta y falsa de dividir a la sociedad. Así rechazan el nacionalismo implícito en "el pueblo" y optan por defender la libertad de los mercados y el libre movimiento de la gente. b) si los populistas enfatizan los mecanismos que le da voz directa al pueblo (referéndums, plebiscitos, etc.), los anti-populistas creen que son mecanismos que llevan al gobierno de la turba. De aquí que los anti-populistas hagan hincapié en la "racionalidad", las buenas maneras, el respeto por los procedimientos y el consenso como la formal "normal” de hacer política. Moffitt rechaza el antipopulismo porque adolece de debilidades. En primer lugar, parece una reactualización de la "tercera vía" - promovida en los años noventa por el primer ministro británico Tony Blair y el sociólogo Anthony Giddens - que no parece ser aconsejable para el funcionamiento de la democracia, ya que cuando los partidos políticos principales convergen al centro ésta se vacía y los políticos dejan de responder las demandas de los votantes. En segundo lugar, crea una atmósfera en la cual cualquier político que se desvíe de la "norma" es etiquetado como populista y desacreditado. Se mete entonces en la misma bolsa a políticos como Trump y Sanders. En tercer lugar, tiende a reforzar la falsa oposición entre liberalismo (gobierno de la ley, la libertad de expresión y los frenos y contrapesos) y democracia (soberanía popular y mayorías). Pero además lo rechaza porque el anti-populismo simplemente no funciona. No existe evidencia empírica que lo avale. Muy por el contrario, enumera una serie de ejemplos con los que demuestra que las tácticas anti-populistas en muchos casos sólo han servido para reforzar a los populismos. Podemos decir que todos los elementos vertidos en el análisis de estos autores resultan valiosos y pertinentes también para el análisis del anti-populismo argentino, inclusive muchos de ellos podrían aplicarse a la AC. Sin embargo, estos trabajos nada dicen respecto del afecto allí implicado. En este sentido, creemos que el caso argentino sirve de muestra de que el afecto anti-populista fundamental es el odio y que éste resulta así ser su factor estructurante.

El psicoanálisis nos ofrece herramientas teóricas que nos auxilian a la hora de pensar el odio a partir de indicios. Tanto Freud como Lacan abordaron la cuestión en diversos pasajes de sus obras. Sin pretender agotarlos tomaremos algunos aspectos trabajados en ellos estando atentas a que los abordajes freudianos y lacanianos explican el odio segregacionista de los fenómenos de masas que siguen la estructura del nazismo. En donde el objeto odiado es el afuera constitutivo de un colectivo configurado en torno de un líder. La exclusión de un otro como excreción delimita las fronteras del grupo así constituido afirmando su identidad. Sostenemos que sería imprudente trasladar sin más este esquema al estudio de los fenómenos en Latinoamérica y en Argentina en particular. No es lícito hacerlo ni para analizar al populismo, ni al antipopulismo. Por un lado, porque lo que definimos como pueblo, en el sentido laclausiano, no es equivalente a la masa freudiana. ${ }^{8}$ Y por otro lado, porque los lazos identificatorios que conforman el colectivo que estamos estudiando (el anti-populismo argentino), no se funda en el amor a un líder, sino en el odio al pueblo y a su líder. Habiendo hecho esta aclaración avancemos sobre el tema.

A diferencia del amor - afecto que no requiere ser sostenido por argumentaciones ya que, en términos generales, socialmente posee una carga asociativa predominantemente positiva, además de que bien se ama sin saber razonablemente el por qué-, el odio debe tener una explicación de parte del odiador, no importa cuán delirante que ésta pueda llegar a ser. Se odia por un motivo, sólo cuando el odiador puede hacer circular su odio en una cadena significante puede volverse causa política. El odio por el odio mismo no cabe en el espacio de los intercambios políticos institucionalizados de la democracia, en donde se espera que impere la razón argumentativa. Éste debe darse una razón para que ese afecto socialmente despreciable quede entretejido en un discurso que halle un lugar en las prácticas políticas sedimentadas de la democracia. Debe hacerse de una cadena significante. Lanata con sus piezas discursivas nos da un indicio de esa cadena de significantes. El significante sobredeterminado de la última versión del odio anti-populista es "el kirchnerismo", condensa en sí el mal, la corrupción y la impostura. El kirchnerismo es culpable de "la grieta”, "lo peor que nos pasa” (el 
mal), "los kirchneristas son chorros...” (la corrupción) y además “...con máscaras del Che Guevara” (la impostura). Pero también el kirchnerismo tiene una líder, "que ojalá (la historia) la juzgue como la mierda que fue", a quien se execra y que en primera persona encarna el mal, la corrupción y la impostura, por ello es investida con la mayor cuota de odio. Halla así el odio su justificación, y queda habilitado para volverse pasible de una articulación política.

El anti-populismo tiene al odio como factor estructurante. En Psicología de las masas y análisis del yo (1921), Freud sostiene que el odio puede ser el punto de anudamiento en un agrupamiento social. Por ello Laclau, atento lector de Freud, plantea la posibilidad de que también sea el odio el afecto que comande el lazo que permite la conformación de colectivos. En La razón populista (2005) tomando a Freud dice: "el odio a determinada persona o institución puede producir el mismo efecto unitivo, y generar ligazones afectivas similares a la dependencia positiva" (Laclau, 2005: 85). Este es el caso del anti-populismo. Los anti-populistas tienen en común aquello que rechazan. La identificación entre anti-populistas nace del rasgo compartido que es la aversión por el pueblo y su líder. Es decir, el odio funciona como argamasa de un cierto "nosotros" que se define en función de aquello que se detesta. Lacan continúa por el sendero trazado por Freud y sostenido posteriormente por Laclau, pero lo lleva más allá. Dice Lacan: "Se puede percibir en efecto su equivalente en la comunión que se establece entre dos personas en el odio hacia un mismo objeto: con la salvedad de que el encuentro nunca es posible sino sobre un objeto únicamente, definido por los rasgos del ser al que una y otra se niegan" (Lacan, 1966: 31). Es decir, concuerda con la afirmación de que el odio posee un "efecto unitivo", porque puede haber una comunión/encuentro en función de un objeto que se odia, pero agrega Lacan algo más: ese odio apunta al ser del otro, a quien cuyos rasgos del ser se niegan. De allí que el anti-populismo niegue al pueblo y sus líderes y que su tarea política, cuando logra darse una expresión política, sea siempre extirpar al pueblo, su líder y, con ello, toda forma de populismo del entramado social. Ahora bien, cabe en este punto una decisiva aclaración: "extirpar" al pueblo, no quiere decir solamente provocar un genocidio (como sí lo hizo la última dictadura cívico-militar), sino que la tarea de eliminar al pueblo y sus líderes puede también consistir en la pretensión de borrar sus marcas en lo simbólico, esto es, eliminar sus huellas del campo social. ${ }^{9}$ Como dice Juan Bautista Ritvo: "sin duda no es lo mismo discriminar que segregar ni segregar se confunde con exterminar, pero estos grados reconocen, a la vez, continuidad y discontinuidad." (2006: 195). En todo caso, por estas razones no debe sorprendernos que cuando una agrupación política construida desde el anti-populismo se hace del gobierno proceda a perseguir los líderes populistas y apunte a desarticular las expresiones y organizaciones que el pueblo se pueda dar.

Retomemos aquí los argumentos de un texto anterior (Biglieri y Perelló, 2018) en el cual recurrimos a la noción de posdictadura de Silvia Schwarzböck (2015). La autora definió a la postdictadura como "lo que queda de la dictadura, de 1984 hasta hoy, después de su victoria disfrazada de derrota” (2015: 23). Según la autora no hubo una derrota del proyecto de la dictadura cívico-militar, sino por el contrario, éste continuó bajo la forma de una postdictadura. ${ }^{10}$ Lo que quedó fue la derrota del campo popular y la institución de una vida de derechas (evidenciada sobre todo durante la década de la presidencia de Carlos S. Menem entre 1989 y 1999). Por esto sostuvimos, siguiendo el hilo iniciado por Schwarzböck, que la marca de la posdictadura es la ausencia del pueblo, esto es, el triunfo del odio anti-populista. Allí, yace la victoria política (disfrazada de derrota) de la última dictadura cívico-militar. Si lo que ha dominado la vida política de los argentinos - por lo menos desde 1955 a esta parte- es el odio anti-populista bajo distintas versiones de formaciones políticas (golpes de estado, extendida proscripción del peronismo, etc.), sólo la última dictadura cívico-militar fue eficaz en su tarea de eliminar al pueblo. Porque a excepción de algunos breves y acotados episodios del alfonsinismo la figura del pueblo no volvió a articularse como una cadena estable de significación en la vida política de la Argentina hasta la formación del populismo kirchnerista. Aquello que quedó de la dictadura cívico-militar como ausencia desde fines de 1983 fue puesto en entredicho 20 años más tarde con la llegada de Néstor C. Kirchner a la Presidencia de la Nación. Por esto, es que afirmamos que el kirchnerismo puso fin al orden dispuesto en la posdictadura, un orden que la AC intentó restaurar durante su gobierno entre 2015 
y 2019. La AC es la última versión política del anti-populismo que logró alzarse con el gobierno nacional y su tarea no fue otra que eliminar al pueblo (kirchnerismo) y perseguir a sus dirigentes y su líder.

Queremos destacar en este punto un pasaje de Freud que toma al odio no sólo en relación al amor sino también con la indiferencia. En su texto Pulsiones y destinos depulsión (1915), Freud cuestiona las perspectivas que definen al odio como la contracara del amor, como si fueran el anverso y reverso de una misma hoja de papel. Desde el campo popular, por ejemplo, muchas veces el odio al líder es considerado como el reverso del amor que el pueblo tiene por él/ella. Para Freud el amar tiene múltiples contrarios. dice: "el amar no es susceptible de una sola oposición [amar/odiar], sino de tres". El amar se opone: a odiar, a ser amado y a la indiferencia. (1915; 128). Respecto del par amar odiar, el odio tiene un carácter primordial para el yo ya que “es, como relación con el objeto, más antiguo que el amor" (1915: 133). El odio es presentado entonces como una repulsa inmunitaria que emerge desde la misma constitución del yo (narcisista) para oponerse a aquello (los estímulos) que se presenta como una amenaza que proviene del mundo exterior. Por ello afirma que "los genuinos modelos de la relación de odio no provienen de la vida sexual, sino de la lucha del yo por conservarse y afirmarse" (1915: 132). En todo caso, el amor y el odio no tienen un origen en común y mantienen entre sí una relación compleja que toma la forma de una oposición binaria (amor-odio) cuando aparecen bajo la influencia de la relación placer-displacer. Es este formato binario el que le permite a Freud sustentar su tesis de la ambivalencia afectiva, el amor se mezcla con el odio, el cual persiste y "se remota a la fuente de las pulsiones de conservación del yo". Y le permite además explicar por qué el amor también puede mudar en odio, "cuando el vínculo de amor con un objeto determinado se interrumpe, no es raro que lo remplace el odio, por lo cual recibimos la impresión de que el amor se muda en odio" (1915: 134). Pero si atendemos a la nota al pie de Strachey (130), el comentarista encuentra en este mismo texto de Freud un reordenamiento de la secuencia que se lo adjudica a un orden lógico de surgimiento de estos pares de oposiciones. Así, señala que Freud le otorga al par binario amar/indiferencia una prioridad lógica frente al amar/odiar. Es decir, la indiferencia es precursora del odio. La indiferencia como momento lógico anterior al odio se refiere a aquel en el que el yo es investido por todas las pulsiones y encuentran en sí mismo su satisfacción. En este escenario, que Freud llama narcicismo, la satisfacción pulsional no requiere de un objeto externo, es autoerótica y hacia afuera sólo hay indiferencia. Amar/indiferencia es entonces la oposición primigenia, el amarse a sí mismo frente a la indiferencia hacia el mundo exterior. Pero si esa indiferencia es perturbada por el exterior lo que sigue es el odio. Por ello para odiar antes habremos sido indiferentes.

La indiferencia hacia lo social es el dominio de la vida de derechas, que en los tiempos que corren no es otra cosa más que el imperio de la subjetividad neoliberal. Wendy Brown (2015) le da el nombre de capital humano a este modo de subjetivación. Una vez que nuestra subjetividad ha sido emplazada en términos de capital humano ningún rincón de nuestras almas queda exento de ser sometido al imperio del sacrificio meritocrático en favor del buen orden de los mercados. La subjetividad neoliberal se vuelve así un terreno fértil para las exigencias más severas del superyó ${ }^{11}$ : siempre se le puede exigir más rendimiento al capital (humano), se puede hacer más mérito y en todo momento va a estar bajo la amenaza de volverse prescindible para el mercado si pierde competitividad. Y si esto último resulta ser así, frente a la mirada impasible de los otros competidores la culpa caerá sobre el propio individuo que no supo, no pudo o no quiso hacer un esfuerzo mayor o un sacrificio más de sí. Así, hacia afuera, hacia el otro sin mérito, manda la indiferencia. La vida de derechas se vuelve un campo fértil para propalar odio.

Por esto la tarea anti-populista muchas veces -aunque no exclusivamente- va de la mano del anhelo por instaurar una vida de derechas, ya que ésta aspira a la realización de un dominio del homo oeconomicus -bajo la forma subjetiva del capital humano- por sobre el homo politicus. Es decir, pretende una vida sin política, sin antagonismos, y por sobre todo sin antagonismos populistas en donde un pueblo y su líder -con la división dicotómica del espacio social- pongan en entredicho el statu quo neoliberal al pujar por otras formas de subjetivación y lazo social que escape a la lógica del capital humano. La vida de derechas encierra la fantasía 
del grado cero del populismo, de la sociedad sin "grietas", en donde no haya ningún pueblo que corrompa la disposición de lugares, jerarquías y funciones que la sociedad meritocrática pretende instalar.

El populismo perturba la indiferencia de la vida de derechas también por eso se lo odia. La demanda del agraviado le es indiferente a quien anhela una vida de derechas, espera -en el mejor de los casos- que ésta sea canalizada por las vías de intercambios políticos instituidas o que cada quien tramite su propia insatisfacción individualmente o que resuelva su agravio a través de un mayor sacrificio. Pero cuando esa demanda permanece insatisfecha y logra articularse de manera más extensa en un pueblo, la indiferencia, que ya no es sostenible frente al antagonismo que plantea un populismo, muta en odio.

Ahora bien, volvamos sobre la tarea anti-populista de eliminar al pueblo y sus liderazgos, para detenernos en aquello que trajimos líneas atrás respecto de lo que Lacan denomina como el odio al ser del otro. Porque este aspecto nos permite ver que hay algo más allí en lo que ya hemos analizado, por un lado, como odio en tanto perturbador de la indiferencia narcisista y, por otro lado, como odio al otro en la rivalidad "especular" que opera como rasgo compartido con un grupo que afirma su identidad en el rechazo al semejante (como un antagonismo planteado en términos imaginarios). Es decir, no se trata solamente de la fantasía de que el definitivo sometimiento, derrota o eliminación de aquel con el cual antagonizo me haga alcanzar mi propia plenitud; esto es lo que tradicionalmente encontramos en el anti-populismo argentino que supone que con la eliminación del populismo se sanaría la historia rota de la Argentina y el país podría desandar el desvío que lo alejó de su destino de grandeza. Hay inclusive un odio más radical que no se solaza con el dominio sobre el otro y que se vincula al goce.

Lacan a partir de 1964 aborda el tema del odio, profetizando el ascenso del racismo, en términos de una economía de goce. Desde esta perspectiva Miller dirá que el odio que se conoce a través del racismo moderno (y de otras formas semejantes de segregación) no es mera agresividad, "hay una consistencia de esta agresividad que merece el nombre de odio y que apunta a lo real en el Otro." Ese odio que apunta al ser del Otro, y hace de él una alteridad radical es el "odio al goce del Otro (...) se odia especialmente la manera particular en que el Otro goza." (Miller; 2010: 53). Como sujetos que habitamos el lenguaje, afectados por la castración (falta) hay una imposibilidad estructural de acceso directo al goce, y esa falta de goce es vivenciada como producto de una sustracción por parte del Otro. La intolerancia al goce del Otro, entonces esconde dos supuestos: por un lado, el robo del goce propio perpetrado por el Otro; y, por otro, que el Otro sí accede al goce plenamente (a costa del mío propio). Lo más íntimo del sujeto está afuera (porque me lo ha robado el Otro), Lacan utilizó un neologismo para designar esta posición paradojal: extimidad. ${ }^{12}$

Así, por ejemplo, encuentran explicación ciertas afirmaciones que resultan ajenas a cualquier debate crítico racional, pero que para el odiador anti-populista adquieren visos de verosimilitud y entonces son repetidas como certezas incontrastables. El indicio que tomamos de Lanata, "los kirchneristas son chorros con máscaras del Che Guevara", se enlaza con otros significantes tales como: "se robaron un PBI", "se robaron todo", "son todos chorros", "son todos corruptos”, etc. Porque ese Otro encarnado parcialmente en esos otros, el/la líder, los dirigentes y los miembros identificados como parte de ese pueblo, se robaron aquello que me impide alcanzar mi propio goce. Los populistas capturan todo el goce para sí mismos, dejando a los demás sin nada. Pero además son impostores (usan "máscaras del Che Guevara") que aquello que se roban lo mal gastan en una fiesta impúdica que no guarda relación con la ampliación de derechos que el kirchnerismo aduce encarnar. Así encontramos significantes como: "la Asignación Universal por Hijo (AUH) se está yendo por la canaleta de la droga y el juego", 13 “se embarazan por un plan", "van a los actos por el choripán”, "le hicieron creer a un empleado medio que su sueldo servía para comprar celulares, plasmas, autos, motos e irse al exterior”, ${ }^{14}$ etc. Tal obscenidad populista se condice con el tratamiento periodístico del liderazgo de Cristina Fernández de Kirchner, por ejemplo, en las tapas de la Revista Noticias en donde se muestra a la ex-presidenta teniendo un orgasmo, al fin y al cabo, nada más indignante para el anti-populista que esa líder que tanto odian y no los conduce, sea quién más goza. ${ }^{15}$ 
El puro odio destruye el vínculo con los otros y la pulsión queda enlazada con un goce narcisista mortífero. A diferencia del caso en el cual se presenta bajo el par binario amor/odio (que es el que propicia el lazo social y permite morigerar las pulsiones destructivas poniéndolas en juego en esos vínculos, en una suerte de erotización de las pulsiones tanáticas), el odio deschavetado no encuentra qué lo amortigüe. Se exige el castigo más severo para aquel odiado, incluso su pública humillación: hay que mostrarlos esposados en pijamas como fue el caso del ex-Vice Presidente Amado Boudou ${ }^{16}$, u otorgarle la prisión domiciliaria a la líder de la agrupación kirchnerista Tupac Amaru, Milagro Sala, en una casa inhabitable ${ }^{17}$, etc.

Para finalizar hay dos aspectos más, que se desprenden de esta oscura pasión, que queremos señalar. En primer lugar, aquello a lo que Jorge Alemán refiere como una nueva definición de maldad: "hacerse daño a sí mismo con tal de perjudicar al otro" (2020). Cuando al otro se lo execra o simplemente no se lo soporta, el odio puede llevar a sostener posiciones políticas que, aún a sabiendas de que son perjudiciales para sí mismo, buscan humillar, destruir o evitar que el otro vuelva a salir victorioso en una contienda electoral. Conjeturamos que encontramos aquí una explicación de porqué gran parte de la ciudadanía argentina siguió apoyando a la AC en las elecciones generales de 2019 aún a pesar del deterioro económico generalizado y el retroceso en materia de derechos. En segundo lugar, y en relación con lo anterior el odio al líder invalida la argumentación crítica del espacio público y anula la posibilidad de negociación política, porque no hay nada que el líder diga o haga, ni gesto o propuesta que presente, ni medida que tome, aún aquella que beneficie a algún sector identificado con el anti-populismo, que no sea motivo de rechazo. De esta forma, el odio antipopulista pone en entredicho una de las prácticas fundamentales de la vida democrática, como es el debate que hace discurrir posiciones políticas encontradas.

\section{CONSIDERACIONES FINALES}

Retomemos las preguntas que orientaron este ensayo respecto del lugar que ocupa el odio en el armado antipopulista, y vemos en nuestro análisis que no se trata de un epifenómeno de "la vida de derechas" como idea fuerza que los nuclea, ni tampoco es el correlato de la ambivalencia afectiva hacia un líder que conduce a esa comunidad de personas, sino que el odio está en la raíz del armado anti-populista. Y pudimos repasar en el caso que ocupó nuestro análisis, cómo opera como factor estructurante del colectivo que conforma la AC. Hemos encontrado las huellas de este odio en la situación inédita en nuestra historia reciente, en el período en que una articulación política anti-populista logra hacerse del poder político a través las vías democráticas plenamente vigentes y cómo éstas huellas han tensado y puesto en entredicho la vida política democrática reciente. En un contexto global signado por el emplazamiento subjetivo neoliberal que Brown denomina capital humano. En este escenario trasnacional se ven facilitadas las condiciones para que el odio como factor político encuentre su eficacia. La ruptura del lazo social en el individualismo, la carrera competitiva meritocrática entre capitales humanos que no conoce los vínculos solidarios, tienen como correlato afectivo la indiferencia social y el odio, limitando al ámbito privado los lazos más amorosos. Este escrito no tiene la pretensión de agotar el tema abordado, sino más bien de explorar las ideas que logren sustentar una hipótesis bien fundada.

\section{REFERENCIAS}

Alemán, J. (2020). “El racismo es el odio del goce del otro". En The Clinic. Disponible en: https://www.theclinic.cl/2 018/08/02/jorge-aleman-racismo-odio-del-goce-del/, accedido el 9/03/2020.

Biglieri, P. (2007), "El retorno del pueblo argentino: entre la autorización y la asamblea. Argentina en la era K”. En Biglieri, Paula y Perelló Gloria, En el nombre del pueblo. La emergencia del populismo kirchnerista, Buenos Aires, UNSAM Edita, pp. 61-84.

Biglieri, P. y Perelló, G. (2012), Los usos del psicoanálisis en la teoría de la hegemonía de Ernesto Laclau, Buenos Aires: Grama Ediciones. 
Biglieri, P. y Perelló, G. (2018), “Populismo y retorno neoliberal. Algunas reflexiones tardías sobre el kirchnerismo y tempranas sobre el macrismo”. En Ecuador Debate, número 104, Quito: agosto de 2018, pp. 67-81.

Brown, W., (2015), Undoing the demos. Neoliberalism's Stealth Revolution, New York, Zone Books.

Freud, S. (1915), "Pulsiones y destinos de pulsión" en Obras Completas, vol. XIV, 1914-1916, Buenos Aires: Amorrortu editores, 2008, pp. 105-134.

Freud, S. (1921), "Psicología de las masas y análisis del yo", en Obras Completas, 1920-1922, vol. XVIII, Buenos Aires, Amorrortu Editores, 2008, pp. 65-136.

Galanopoulos, A. (2020), “Anti-populism and 'normality' from Greece to Chile”, en Open Democracy, https://www.opendemocracy.net/en/democraciaabierta/anti-populism-and-normality-from-greec e-to-chile/?fbclid=IwAR0xrFHDNm-Do4F6-IYXa3tNYNaixvIx5RhmAE5IgeMOeDegEazKYjURnc4

Galanopoulos, A. y Stavrakakis, Y. (2019), Populism, Anti-populism and Post-truth in Crisis-ridden Greece, en Populismus, http://www.populismus.gr/.../up.../2019/10/WP-10-upload-2019.pdf, accedido el 18/2/2020.

Ginzburg, C. (2008), Mitos, emblemas, indicios. Morfologia e historia. Barcelona: Gedisa.

Lacan, J. (1959-1960). El seminario. La ética (Vol. Libro 7). Buenos Aires: Paidós. 1988

Lacan, J. (1966). El seminario sobre "la carta robada", en Escritos I (3a ed. rev. y corr ed.). (T. Segovia, \& A. Suárez, Trads.) México: Siglo XXI, 2009.

Laclau, E. y Mouffe, C. (1985), Hegemonía y estrategia socialista. Hacia una radicalización de la democracia, Buenos Aires: FCE, 2007.

Laclau, Ernesto (2005), La razón populista, Bueno Aires: FCE.

Miller, J.-A. (2010), Extimidad. (N. González, Trad.) Buenos Aires: Paidós.

Moffitt, B. (2020), "The trouble with anti-populism: why the champions of civility keep losing", en The Guardian, https ://www.theguardian.com/politics/2020/feb/14/anti-populism-politics-why-champions-of-civility-keep-losin g?fbclid=IwAR0j8R0ilG5fWQZichxqpdRThaQkB26BF6kau3xMytXxZfUzZNYg7XOwCvk

Ritvo, J. B. (2006), Figuras del prójimo. El enemigo, el otro cuerpo, el huésped. Buenos Aires: Letras Viva.

Schwarzböck, S. (2015), Los espantos. Estética y postdictadura, Buenos Aires, Cuarenta Ríos.

\section{Notas}

1 Jorge Lanata es un operador político, conductor de tv y radio y periodista que durante los gobiernos kirchneristas (2003-2015) sostuvo un sesgo abiertamente opositor al oficialismo y apoyó a la Alianza Cambiemos liderada por Mauricio Macri que fue gobierno entre 2015-2019. Protagonizó entre otros el programa Periodismo para todos que se televisaba través de la pantalla de uno de los canales de tv del Grupo Multimedia Clarín. En ese programa estuvo fuertemente focalizado en presentar informes de investigación en los cuales se denunció una suerte de corrupción sistémica de parte del kirchnerismo. Algunas de estas denuncias posteriormente fueron directamente descartadas por la administración de justicia, mientras que otras fueron el puntapié del lawfare que dominó la política judicial antipopulista durante el gobierno de Macri. Respecto del discurso de Lanata al que aquí hacemos referencia ver: https://w ww.youtube.com/watch?v=LcLR0R9PliQ\&feature=youtu.be, accedido el 10/02/2020.

2 Los premios Martín Fierro son galardones que la Asociación de Periodistas de la Televisión y la Radiofonía Argentinas (APTRA) otorga desde 1959.

3 Lanata, Jorge, https://www.youtube.com/watch?v=Fcd9iVDQW7E, accedido 10/02/2020.

4 En octubre de 2016 Cristina Fernández de Kirchner ya había dejado la Presidencia de la Nación. La editorial de Lanata tuvo lugar después de que no se presentó a una mediación por una denuncia que la ex-presidenta presentó en s contra por difamación y falsedad ideológica a raíz de un informe que había presentado en su programa. Respecto de la editorial de Lanata ver: https://www.youtube.com/watch?v=vvEakh-O-xI, accedido 24/02/2020.

5 Durante 2008 tuvo lugar lo que mediáticamente se denominó como "el conflicto con el campo". Se trató de una disputa antagonista, que enfrentó al gobierno de Cristina Fernández de Kirchner con las organizaciones patronales agropecuarias, y desató la toma de partido ya sea por una u otra posición, por parte de muchos argentinos. Este antagonismo, que comenzó cuando el gobierno nacional sacó una resolución ministerial que cambió la forma de tributar de las exportaciones del agro, aunque se extendió durante unos cuatro meses, se inscribió como una huella que perdura 
y que reverbera en la oposición populismo - anti-populismo o kirchnerismo vs. anti-kirchnerismo que ha marcado la vida política argentina desde los primeros años de este siglo.

6 En textos anteriores, siguiendo las categorías propuestas por Laclau y Mouffe (1985) y Laclau (2005), hemos argumentado sobre el carácter inherente del antagonismo en cualquier espacio social, la dimensión constitutivamente autoritaria que encierra la pretensión de eliminarlo y hemos trabajado también como ese antagonismo inerradicable ha tomado la forma populista en la medida en que el espacio social está dividido en dos lugares de enunciación "el pueblo" vs. "sus enemigos" o "kirchnerismo" vs. "anti-kirchnerismo". Ver: Biglieri, 2007, 2012 y Biglieri y Perelló, 2018.

7 Los elementos que condensaron la campaña electoral de la AC fueron: "unir a los argentinos", "pobreza cero" y "combatir al narcotráfico”.

8 Ver Biglieri y Perelló 2012.

9 Del caso argentino el ejemplo típico que podemos traer aquí es el del decreto 4161 publicado en el Boletín Oficial el 9 de marzo de 1956 firmado por el presidente de facto general Pedro E. Aramburu, de la dictadura autodenominada Revolución Libertadora, citamos el primer artículo completo porque es claro caso de un intento de borramiento simbólico. Art. 1: "Queda prohibida en todo el territorio de la Nación: a) La utilización, con fines de afirmación ideológica peronista, efectuada públicamente, o propaganda peronista, por cualquier persona, ya se trate de individuos aislados o grupos de individuos, asociaciones, sindicatos, partidos políticos, sociedades, personas jurídicas públicas o privadas de las imágenes, símbolos, signos, expresiones significativas, doctrinas artículos y obras artísticas, que pretendan tal carácter o pudieran ser tenidas por alguien como tales pertenecientes o empleados por los individuos representativos u organismos del peronismo. Se considerará especialmente violatoria de esta disposición la utilización de la fotografía retrato o escultura de los funcionarios peronistas o sus parientes, el escudo y la bandera peronista, el nombre propio del presidente depuesto el de sus parientes, las expresiones «peronismo», «peronista», «justicialismo», «justicialista», «tercera posición», la abreviatura PP, las fechas exaltadas por el régimen depuesto, las composiciones musicales «Marcha de los Muchachos Peronista» y «Evita Capitana» o fragmentos de las mismas, y los discursos del presidente depuesto o su esposa o fragmentos de los mismos. b) La utilización, por las personas y con los fines establecidos en el inciso anterior, de las imágenes, símbolos, signos, expresiones significativas, doctrina artículos y obras artísticas que pretendan tal carácter o pudieran ser tenidas por alguien como tales creados o por crearse, que de alguna manera cupieran ser referidos a los individuos representativos, organismos o ideología del peronismo. c) La reproducción por las personas y con los fines establecidos en el inciso a), mediante cualquier procedimiento, de las imágenes símbolos y demás, objetos señalados en los dos incisos anteriores. Pero también encontramos ejemplos, en un punto más sutiles pero por ellos no menos significativos, durante la experiencia del último gobierno anti-populista que expresó la AC: la prohibición de llamar al Centro Cultural Kirchner por su nombre completo para dejarlo reducido a CCK, el intento de aprobar una ley por la cual se reemplace el nombre Kirchner de los espacios públicos (ver: https://www.tiempoar.c om.ar/nota/el-gobierno-intenta-quitar-el-nombre-de-kirchner-de-edificios-publicos, accedido06/03/2020.), retirar el busto de Néstor C. Kirchner de la plaza del Municipio de Morón, cambiarle el nombre Néstor Kirchner al auditorio de Radio Nacional Córdoba (ver: https://www.perfil.com/noticias/politica/cordoba-le-quito-el-nombre-nestor-kirch ner-a-un-auditorio.phtmlde, accedido el 06/03/2020), despedir empleados públicos acusados de ser la "grasa militante" kirchnerista (https://www.politicargentina.com/notas/201601/11044-prat-gay-queremos-un-estado-sin-la-grasa-de-1 a-militancia.html, accedido 06/03/2020), etc.

$10 \mathrm{La}$ autora hace referencia a la última dictadura cívico-militar que vivió la Argentina y que transcurrió entre marzo de 1976 y diciembre de 1983, cuando Raúl R. Alfonsín por la Unión Cívica Radical (U.C.R.) resultó ser el presidente legítimamente electo según los mandatos constitucionales.

11 Trabajamos cómo funciona el superyó en los tiempos de subjetividad neoliberal en la AC en Biglieri y Perelló, 2018

12 Lacan afirma: "Quizá lo que describimos como ese lugar central, esa exterioridad íntima, esa extimidad, que es la Cosa, esclarecerá la pregunta que aún subsiste, el misterio incluso que representa para quienes se interesan en el arte prehistórico - a saber, precisamente su emplazamiento." (Lacan, 1959-1960/1988, 171).

13 Ver: https://www.lapoliticaonline.com/nota/nota-65548/, accedido el 07/03/2020.

14 Ver: https://www.infobae.com/2016/05/27/1814472-gonzalez-fraga-le-hicieron-creer-un-empleado-medio-que-podi a-comprarse-celulares-e-irse-al-exterior/, accedido el 07/03/2020

15 https://noticias.perfil.com/noticias/general/2012-09-07-el-goce-de-cristina.phtml

16 https://lavozdiario.com.ar/nota/12268/boudou-sobre-las-fotos-en-pijama-fui-obligado-a-posar, accedido 20/03/2020.

17 https://www.pagina12.com.ar/57054-una-medida-que-es-parte-del-hostigamiento, accedido el 10/03/2020 